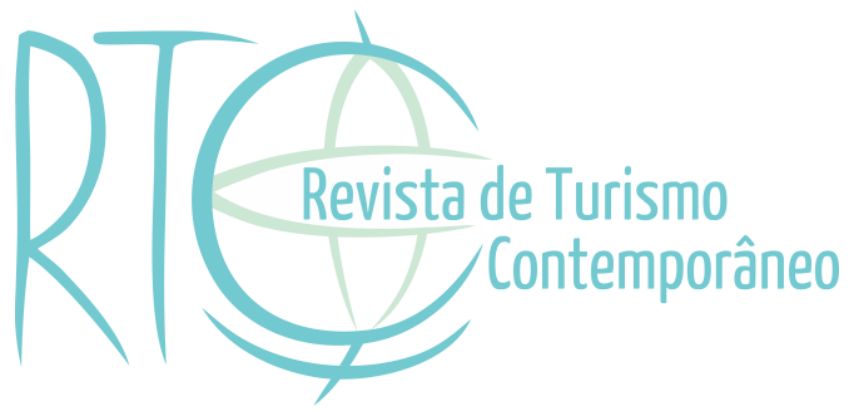

\title{
A trajetória histórica da institucionalização do turismo no Brasil
}

The historical trajectory of the institutionalization of tourism in Brazil

Christiano Henrique da Silva Maranhão

Doutor em Geografia pela Universidade Federal do Rio Grande do Norte - UFRN, Natal/RN, Brasil

E-mail: christianomaranhao@gmail.com

Artigo recebido em: 28-05-2016

Artigo aprovado em: 13-10-2017 


\title{
RESUMO
}

Este artigo teórico tem como objetivo geral estruturar os principais subsídios que demarcam a trajetória histórica da institucionalização do turismo no Brasil, levantando e correlacionando algumas das iniciativas estatais basilares da conjuntura estudada (decretos, marcos legais, políticas, projetos, planos e programas). Justifica-se o estudo, por entender que os padrões históricos pelos quais o turismo foi promovido no Brasil, ainda influenciam na forma como a atividade se materializa na contemporaneidade. Metodologicamente, o artigo se caracteriza como exploratório-descritivo e faz uso da pesquisa bibliográfica como ferramenta técnica. Busca-se a partir de um processo interativo de pesquisa, coletar, descrever e explicar dados e informações, promovendo a devida ordenação e possibilitando o cruzamento de subsídios e a devida interpretação. Com efeito, considera-se que a falta de preparo para a gestão e planejamento do turismo no Brasil é histórica. Destaca-se a centralidade no viés econômico do turismo como o aspecto que limitou ações de escopo mais amplo. Conclui-se que, enquanto a visão econômica sobrepor à compreensão do turismo enquanto fenômeno social complexo, as ações promovidas pelo poder público continuaram reforçando os hiatos sociais já existentes no país, contrariando inclusive, a ideia difundida nos discursos políticos que tratam do turismo, enquanto uma possibilidade de minimizar desigualdades regionais.

Palavras-chave: Turismo. Trajetória Histórica. Institucionalização. Estado. Política Pública.

\begin{abstract}
This theoretical article aims to structure the main subsidies that mark the historical trajectory of the institutionalization of tourism in Brazil, raising and correlating some of basic initiatives of the conjuncture studied (decrees, legal frameworks, policies, projects, plans and programs). However, the study, as understood in regard to the pattern, in Brazil, still has influence on the way an activity materializes in contemporaneity. Methodologically, this article is characterized as exploratory-descriptive, and makes use of bibliographical research as a technical tool. It seeks from an interactive process of research, to collect, to describe and to explain data and information, promoting to proper ordering and allowing the crossing of subsidies and a due interpretation. In fact, it is considered that the lack of preparation for a management and planning of tourism is historical in Brazil. The centrality in the economic bias of tourism is highlighted as an aspect that limits the actions of a broader scope. It is concluded that, as long as the economic vision overlaps the understanding of tourism as a complex social phenomenon, the actions promoted by the continuous public power reinforcing the already existing social gaps in the country, even contradicting the idea disseminated in the political discourses that deal with tourism, a regional inequalities.
\end{abstract}

Keywords: Tourism. Historical Trajectory. Institutionalization. State. Public Policy. 


\section{INTRODUÇÃO}

Refletir e estruturar os fatos que compõem a trajetória histórica sobre a institucionalização do turismo brasileiro é antes de tudo um desafio, e requer um esforço de correlacionar as diversas ações que marcam este percurso desde 1930, diante da criação do primeiro organismo público de turismo no Brasil (Divisão do turismo), que fiscalizava as atividades ligadas às agências de viagem (Endres, 2012).

Percebe-se que o turismo neste momento inicial não captava um significativo empenho do Estado, fato expresso pelos inúmeros decretos de lei, dotados de conteúdos frágeis e sem articulação entre si e/ou entre outras políticas setoriais, que só ratificavam que o turismo não era área de preocupação estatal quando comparado à Educação, Saúde, Segurança, e de igual modo, quando nivelado a outras atividades econômicas, como agricultura e indústria (Cruz, 2000).

Este panorama modifica-se a partir da década de 1980, em meio a um período de dificuldade econômica mundial, comumente conhecido como "década perdida". Observa-se que a demanda por estimular a economia fragilizada e a busca por novas alternativas diante da crise (possibilidades de geração de renda), encontra respaldo no inerente movimento econômico promovido pela atividade turística. Foi assim que o turismo passou a captar a devida atenção estatal. (Cerqueira et al. 2008, p. 2) enfatiza que "a legislação de um país representa [...] a importância que o país dá à atividade".

Deste modo, nota-se que a repercussão econômica em torno da atividade turística, reflexo do aproveitamento dos recursos naturais (praias, montanhas, dunas, florestas entre outros) e de bens imateriais (festas típicas, danças, costumes, hospitalidade entre outros) acabou habilitando-o, ao longo de seu percurso histórico, como um promissor vetor de dinamização da economia brasileira, impulsionado sua representatividade e oficialização, enquanto área de atuação estatal. Desde então, é possível destacar certa centralidade no viés econômico quando se pensa em fomentar o turismo no Brasil (Cruz, 2002, Fonseca, 2005 \& Dias, 2008).

Aqui se faz necessário destacar um alinhamento. De fato, o turismo de maneira similar a outras atividades econômicas, possibilita um incremento de divisas nas localidades onde acampa. Podendo ser benéfico (agindo em função da redução das desigualdades regionais) ou de forma diferente, tornando-se um enclave econômico (quando ocorre a vazão da maior parte da receita produzida para os grandes centros e agentes hegemônicos, restando pífias quantias para a localidade). Por isso é preciso cautela no momento de reproduzir certos 
discursos. O turismo não pode assumir uma demanda que não lhe cabe isoladamente. Nem ao menos pode ser visto unicamente como uma alternativa econômica para conjunturas difíceis (Cerqueira, Furtado \& Mazaro, 2009).

Destarte, este artigo teórico apresenta como objetivo geral, estruturar os principais subsídios que demarcam a trajetória histórica da institucionalização do turismo no Brasil, levantando e correlacionando algumas das iniciativas estatais basilares da conjuntura estudada (decretos, marcos legais, políticas, projetos, planos e programas), que delimitam o percurso da materialização da atividade no país.

Posicionar-se sobre uma demarcação fechada e totalitária dos elementos de composição do percurso histórico da atividade turística no Brasil não se configura como objetivo aqui. O esforço desta produção justifica-se pelo entendimento de que os padrões históricos pelos quais o turismo foi promovido inicialmente no Brasil, de certa forma, ainda influenciam na maneira como a atividade é gerida nos dias atuais, principalmente no que concerne o posicionamento do Estado , a estruturação de políticas públicas e o planejamento adotado. Por isso, a relevância de atualizar o levantamento destes fatos, e a partir disso buscar novas correlações e direcionamentos.

Metodologicamente, conforme Veal (2011), este estudo se caracteriza como exploratório-descritivo. Entende-se que a meta de coletar informações já prescritas por outros autores, e posteriormente realizar seu devido cruzamento, buscando identificar relações e possíveis desníveis, já sinaliza para um perfil exploratório, comum nas pesquisas científicas que pautam suas questões na temática do turismo, reconhecida como uma área de estudos recente no país. Ainda meditando sobre o caráter exploratório, é possível apontar o uso da pesquisa bibliográfica como ferramenta técnica utilizada.

Já sobre o viés descritivo, este é utilizado em complemento à perspectiva exploratória. $\mathrm{O}$ ato de explorar e o ato de descrever caminham correlacionados para fins interpretativos (Köche, 2013). Além disso, observa-se que a própria natureza mutante do turismo solicita descrições, que a posteriori, permitem o confronto de padrões e o esclarecimento de alguma discrepância porventura identificada. Por isso, aponta-se que o referido artigo pauta-se em um processo interativo de exploração, coleta, descrição e explicação de dados. Promovendo sua ordenação, de forma a permitir o cruzamento de informações, propiciando a devida interpretação.

De forma complementar, informa-se que este artigo é parte de uma tese, defendida em fevereiro de 2017, no Programa de Pós-graduação e Pesquisa em Geografia, vinculado a UFRN. Na busca por entender como a temática do turismo é estudada pelas pesquisas 
geográficas (teses e dissertações), no âmbito dos Programas brasileiros de Pós-graduação em Geografia, é que se fez mister reconstruir o cenário da materialização do turismo brasileiro, para com isso entender que elementos o turismo vem ofertando ao longo do tempo para que a discussão geográfica aconteça.

Por fim, o empenho deste artigo se direciona para uma análise didática e não finalística sobre a trajetória histórica da institucionalização do turismo no Brasil. Uma vez que outros estudos já foram realizados objetivando delimitar este percurso, e outros ainda virão em complemento cíclico deste, característica peculiar da pesquisa científica. Compreende-se que os eventos históricos são dinâmicos e contínuos, e por essa razão o que se busca neste artigo é propor uma atualização no debate, agregar e avançar no conhecimento já divulgado sobre o turismo, diante de suas múltiplas interfaces e de seu ambiente em constante construção.

\section{A GÊNESE DO TURISMO NO BRASIL}

Quando se avalia os primeiros passos da constituição da atividade do turismo no Brasil, com o devido respaldo do Estado, é possível determinar a década de 1930 como seu marco inicial. Neste período foi criada a "Divisão do turismo", considerada o primeiro organismo público do turismo nacional, com a função de vistoriar as agências de viagem (Endres, 2012).

Após a criação da Divisão do turismo, observa-se o fomento de inúmeros "Diplomas Legais" que objetivavam mesmo que timidamente, normatizar as primeiras ações turísticas de cunho nacional. Para (Cruz, 2000, p. 42), os decretos eram desconexos e limitados, uma vez que analisavam aspectos isolados da atividade. "Falharam [...] por reduzirem o turismo, em aspectos parciais. Esquecendo a abordagem estrutural".

Para ilustrar este cenário que versa sobre o empenho inicial do Estado para com o turismo, por meio da criação dos Diplomas Legais, destaca-se o Decreto-lei no 406 de 04/05/1938, que orientado pela mesma análise fragmentada citada por Cruz (2000), tratava unicamente da venda de passagens aéreas, marítimas e terrestres. Ou seja, limitava-se ao controle da entrada de estrangeiros no Brasil (Dias, 2008).

Paralelo a esta conjuntura, surgia certo consenso sobre quais recursos naturais, poderiam ser associados à práxis da atividade. Para (Cruz, 2000, p. 62) “o binômio sol-praia e ecossistemas como Amazônia e Pantanal”, revelavam naquele momento para o mundo e para os gestores brasileiros, um vasto campo natural, repleto de particularidades por onde a gestão e o planejamento do turismo poderia iniciar no Brasil. 
Com efeito, somente no ano de 1966, é que ocorre o estabelecimento de uma acanhada estrutura federal, com destaque para o Decreto-lei $\mathrm{n}^{\circ} 55$, de 18 de novembro, que recomendava a criação dos seguintes órgãos e instrumentos oficiais: (a) Conselho Nacional de Turismo (CNTUR) - de caráter normativo; (b) Empresa Brasileira de Turismo (EMBRATUR) - órgão executor; e (c) Primeiro Plano Nacional de Turismo (Plantur), que continha atribuições e direcionamentos para os operadores turísticos do Brasil. Sobre o Plantur é importante dizer que ele sequer chegou a ser efetivado, devido à fragilidade relacional entre os agentes (Endres, 2012 \& Fratucci, 2008).

Nota-se que a ideia de turismo, visto como área estratégica, só surge a partir da segunda metade da década de 1960, simultâneo a constituição do CNTur e da EMBRATUR em 1966, podendo a partir deste ponto, apontar certa continuidade nos esforços públicos, com vistas a regulamentar o setor turístico brasileiro.

O fim deste período é marcado pela reestruturação da EMBRATUR, que se torna uma autarquia, e modifica sua denominação para Instituto Brasileiro de Turismo, passando a atuar na formulação, coordenação e execução de uma até então inédita Política Nacional de Turismo (PNT). Todo esse trâmite foi respaldado pela Lei 8.181 de 28/03/1991 (Cruz, 2000, 2002).

Convém pontuar, o surgimento de fundos de incentivo econômico ao turismo. Sabese que no ano de 1971, em conformidade com o Decreto-lei n ${ }^{\circ} 1.191$ de 27 de outubro, foi estabelecido o Fundo Geral de Turismo (FUNGETUR), demarcando certo ineditismo do turismo, que passou a assumir um lugar na gestão pública nacional (Cruz, 2000).

Similarmente no ano de 1974, amparados pelo Decreto-lei $\mathrm{n}^{\circ}$. 1.376, foram instituídos novos fundos de incentivo econômico, a citar: Fundo de Investimentos Setoriais (FISET), Fundo de Investimento do Nordeste (FINOR) e o Fundo de Investimento da Amazônia (FINAM). As benesses desses instrumentos permitiram a captação de recursos para serem aplicados nas regiões Norte e Nordeste, concatenados com os objetivos de integração nacional e de desenvolvimento econômico regional (Endres, 2012).

Por essa razão, é pertinente dizer que de 1971 até os primeiros anos da década de 1980, o modelo turístico adotado pelo Brasil sinalizava para um caráter centralizado e intervencionista do Estado, alinhado com a expectativa do crescimento econômico que estava atrelada ao setor, uma vez que o discurso do turismo como uma atividade que gera emprego e renda, e que favorece a produção e circulação de divisas, florescia no Brasil (Endres, Oliveira \& Oliveira, 2012). 
Contudo, mesmo em face de alguns pontuais avanços, a imprecisão conceitual e estrutural sobre o turismo continuava, dificultando o pleito por um ministério específico, e de igual modo, a inserção do turismo em alguma pasta estatal. Com base em Fratucci (2008) e Cerqueira et al (2009), apresenta-se a listagem das distintas instâncias de gestão do turismo brasileiro, diante o percurso histórico, até chegar ao Ministério do turismo em 2003.

\begin{tabular}{|c|l|}
\hline \multicolumn{2}{|c|}{ Instâncias públicas que regularam o turismo no Brasil de 1939 até 2003 } \\
\hline Período & \multicolumn{1}{c|}{ Instância } \\
\hline $1939-1945$ & Divisão de Turismo e Departamento de Imprensa e Propaganda - Presidência da República; \\
\hline $1945-1946$ & Departamento Nacional de Informação - Ministério da Justiça e Negócios Interiores; \\
\hline $1951-1958$ & Departamento Nacional de Imigração do Ministério do Trabalho, Indústria e Comércio; \\
\hline $1958-1961$ & Comissão Brasileira de Turismo - Presidência da República; \\
\hline $1961-1966$ & $\begin{array}{l}\text { Divisão de Turismo e Certames, do Departamento Nacional do Comércio do Ministério da } \\
\text { Indústria e do Comércio; }\end{array}$ \\
\hline $1966-1990$ & Ministério da Indústria e do Comércio; EMBRATUR e CNTur; \\
\hline $1990-1992$ & Secretaria de Desenvolvimento Regional e EMBRATUR; \\
\hline $1992-1996$ & Ministério da Indústria, do Comércio e do Turismo, e EMBRATUR; \\
\hline $1996-2002$ & Ministério de Esportes e do Turismo, e EMBRATUR; \\
\hline Desde 2003 & Ministério do Turismo e Conselho Nacional de Turismo. \\
\hline & Fuadro 01: Instâncias públicas que regularam o turismo no Brasil de 1939 até 2003 \\
\hline
\end{tabular}

Diante das informações apresentadas no Quadro 01, nota-se que no período de mais de seis décadas (64 anos), o turismo transitou por 10 instâncias estatais diferentes, ratificando a dificuldade de compreensão de sua complexidade. Destaca-se certa instabilidade até o ano de 2003, período que foi instituído um ministério específico.

Tendo exposto, de forma sucinta, o cenário inicial da institucionalização do turismo brasileiro, destaca-se as décadas de 1980, 1990 e 2000. A seleção destes períodos ocorre devido a sua representatividade para com o turismo, enquanto área de interesse da gestão pública brasileira.

Inicia-se pela década de 1980, em face das expressivas mudanças globais que sinergicamente afetaram a práxis do turismo no Brasil, passando pela década de 1990, vista como um divisor de águas para a gestão do turismo brasileiro. Nota-se que essas décadas juntas, fomentaram importantes resultados por meio de políticas, planos e projetos, inserindo relevantes questões como: competitividade, internacionalização e gestão descentralizada, na pauta pública do turismo. Chegando aos anos 2000, marcado por ações que ainda reverberam na contemporaneidade.

\subsection{Década de 1980}


Identificada mundialmente pela crise fordista, a década de 1980 foi marcada por um período de dificuldades e de certa paralisia econômica na América Latina, em consonância com o cenário mundial. Esta conjuntura se deu, de forma principal, devido à dificuldade de incorporação dos elementos do capitalismo, ao modo de produção fordista. Uma vez que a inerente rigidez do sistema fordista acabava atravessando os acordos firmados pelo Estado (Harvey, 2008).

Diante desta realidade instável, é possível pontuar alguns dos seus reflexos para o Brasil, a saber: instabilidade política, crise no petróleo, avanço da dívida externa, cortes econômicos entre outros. Nota-se que este colapso econômico passou a solicitar medidas com vistas em uma maior diversificação das atividades produtivas e/ou novas perspectivas de trabalho, buscando renovar a economia então fragilizada (Fonseca, 2005, Oliveira et al, 2012). É diante desta tensão político-econômica, que o turismo passa a ser visto pelo Estado como uma opção econômica relevante para o momento difícil que o Brasil enfrentava.

Impelido por tal conjuntura, o Estado buscou promover a atividade turística, favorecendo uma massiva vinculação à geração de emprego e renda. Para (Fonseca, 2005, p. 86), é "talvez aqui se possa, parcialmente explicar, as razões para o turismo continuar sendo visto na contemporaneidade no Brasil como solução para gerar emprego e renda aos lugares que o incentivarem".

Com efeito, entende-se que a década de 1980, mesmo diante de algumas dificuldades, promoveu o "credenciamento" do turismo, enquanto área estratégica e geradora de possibilidades para o poder público, com vistas na geração de divisas. Na opinião de (Oliveira et al, 2012, p. 392) "[...] o Estado buscou novas alternativas para a retomada do crescimento econômico [...] O turismo assumiria à condição de estratégia central do governo". Fica nítido que havia uma busca por soluções de curto prazo, devido à dificuldade vivenciada na época. Em razão disso, o Estado acabava desrespeitando alguns prazos e etapas do planejamento, assumindo um papel de controlador da atividade. Nota-se que é de forma apressada, que o turismo passou a ser, expressivamente, inserido nas metas públicas do Brasil, gerando rebatimentos que reverberam até a contemporaneidade.

\subsection{Década de 1990}


Como reflexo do paradigma da economia globalizada, que já produzia novos elementos, dentre eles a competitividade, é que na década de 1990, constata-se novos posicionamentos para o turismo. As vantagens competitivas adquirem relevância, devido o reconhecimento da necessidade de obter requisitos e desenvolver atributos que propiciem melhores condições de competir em relação às condições apresentadas pelos concorrentes (Porter, 1998).

Esta nova perspectiva de mercado, acaba adicionando inéditos subsídios para a promoção turística, como por exemplo: o uso da informação, o incentivo à formação específica, a busca por inovações, qualidade do serviço, a imagem do destino, a sustentabilidade entre outros itens. Todos estes aportes acabaram se desdobrando em diversos elementos, diante do fomento da atividade, como: a subjetividade dos sujeitos, a supersegmentação da demanda, as tecnologias integradas, a competição regida pela inovação dentre outros (Fonseca, 2005 \& Cruz, 2000).

Neste contexto, a década de $1990 \mathrm{fez}$ o turismo transitar por outros caminhos e usar novos recursos, fato que leva (Fonseca, 2005, p. 43) a batizá-la como a "Nova Era do Turismo - NET".

Análogo ao modelo de Estado neoliberal que florescia no país identifica-se uma mutação do arranjo embrionário do turismo de décadas passadas, para um escopo de maior alcance, muito embora ainda estivesse centralizado no efeito econômico, e fortemente marcado pelo pragmatismo, que ainda patrocinava uma leitura simplificada da atividade. Tal fato leva (Fratucci, 2008, p. 17) a dizer que: “A atividade turística era vista [...] como atividade econômica e as dimensões - social, espacial, cultural e mesmo política, não eram motivos de interesse [...], os dirigentes agiam de forma empírica [...], baseados nos discursos das grandes vantagens".

Centralizada no viés econômico, a expansão da atividade turística no Brasil durante os anos 90 ultrapassa as fronteiras nacionais, e o Estado inicia o fomento de políticas públicas, já visando à projeção do Brasil no cenário internacional. Justifica-se este posicionamento, diante da dificuldade do fluxo doméstico fazer uso dos diversos setores que movimentavam as divisas no turismo, como: agências, operadoras de turismo e meios de hospedagem, fator que acabava fragilizando a geração de dinheiro projetada pelos agentes (Cruz, 2000).

Sem embargo, e movido por um perfil competitivo, o Estado seleciona a região Nordeste para iniciar esta abertura internacional, priorizando ações que visavam adequar o território, em função das demandas estrangeiras. A escolha da referida região ocorre em 
função do das altas temperaturas, da extensão da costa, da diversidade natural e da riqueza de manifestações culturais entre outros fatores (Fonseca, 2005).

A principal política de turismo que simboliza a década de 1990 e, que se tornou um marco na internacionalização do turismo no Brasil, é o Programa de Desenvolvimento do Turismo (PRODETUR), que será abordado no tópico que trata das principais políticas de turismo do Brasil.

Neste mesmo período, surge o experimento de agenciar a atividade por meio da instância municipal. Ou seja, impulsionava-se a municipalização da gestão do turismo, por meio de parâmetros territoriais. Assim, é criado o Programa Nacional de Municipalização do Turismo (PNMT), elaborado por uma metodologia estrangeira. Diferente do PRODETUR, que alcançou parte de suas metas, o PNMT não obteve o êxito esperado. A situação caótica e sucateada que os municípios brasileiros apresentavam, principalmente considerando os quesitos econômicos e gerenciais, foi a principal causa do insucesso do Programa (Fratucci, 2008).

Com o término da década de 1990, percebe-se que a atividade turística no Brasil já era conduzida por uma postura mais propositiva por parte do poder público. É nítido o aumento do marco legal em torno do turismo (ações, leis, políticas, decretos, projetos, planos). Constata-se um melhor aproveitamento, já determinado pelo fluxo de turistas internacionais, pelos grandes investimentos realizados na implantação de equipamentos hoteleiros, pela vinda de cadeias hoteleiras de bandeiras internacionais, pelo aumento do número de cursos de turismo de nível superior (Solha, 2004).

Acontecimentos como estes, autorizam afirmar que o turismo já havia passado pelo período de "experiência", e era uma realidade recém-efetivada, mesmo que ainda estivesse subjugada a uma perspectiva econômica limitante. Observa-se que o papel do Estado também se modifica, ele deixa de ter uma atitude controladora, e assume uma postura de condutor e dinamizador, refletindo o caráter neoliberal da época, onde "privilegia a capacidade do mercado, em detrimento da intervenção do Estado" (Cerqueira et al, 2009, p. 3).

\subsection{Década de 2000}

Um dos fatos mais representativos para o turismo brasileiro que se pode citar para esta década foi à criação do Ministério do Turismo (Mtur) em 2003, durante o mandado presidencial de Luiz Inácio Lula da Silva. A atividade, enfim, passava a ter acesso às prerrogativas ministeriais e ser autenticada como instância federal. 
Resultado direto da criação do Mtur, em abril de 2003, surge o Plano Nacional de Turismo (PNT): diretrizes, metas e programas, visto como o principal instrumento de planejamento para o setor turístico desta década. O plano foi estruturado por meio dos resultados de um diagnóstico, que sinalizava os equívocos acumulados pelas gestões passadas. Outro fator relevante deste período foi à instalação da Câmara Temática de Regionalização, iniciando os debates nas reuniões do CNTUR, com uso de elementos e escalas espaciais, até então incomuns para o planejamento do turismo como: descentralização da gestão, dinamização da economia regional, região entre outros, conforme o Ministério do Turismo do Brasil (Brasil, 2015).

Fruto deste debate lança-se o Programa de Regionalização do Turismo (PRT) Roteiros do Brasil, na Confederação Nacional do Comércio (CNC) em Brasília. A partir daí, a premissa de regionalizar o turismo ganha espaço. Vários estudos, debates, leis e propostas passam a se vincular com esta perspectiva, que tem por base as diferentes regiões brasileiras. A temática da regionalização torna-se uma política macro de desenvolvimento do turismo. (Brasil, 2015).

Ainda é possível citar que em 2008, ocorre a sanção da Lei Geral do Turismo (LGT) $\mathrm{n}^{\mathrm{o}}$ 11.771, apresentando um caráter intersetorial, que relaciona suas ações com 12 Ministérios distintos, acenando para um possível entendimento do turismo, enquanto área multifacetada (Cerqueira et al, 2008). Em resumo, entende-se que a década de 2000 apresentou alguns avanços para o turismo no Brasil, verificando a existência de vários desdobramentos que ainda norteiam o planejamento contemporâneo do turismo no Brasil. A seguir, pontua-se brevemente, as principais políticas, planos, programas e projetos ligados ao turismo durante todo este percurso histórico.

\section{LEVANTAMENTO DOS PRINCIPAIS INSTRUMENTOS DE ORDENAÇÃO DO TURISMO BRASILEIRO}

\subsection{Principais programas e projetos do turismo no Brasil}

A partir deste ponto, apresenta-se uma síntese dos principais programas e projetos que compõem a trajetória pública do turismo nacional. Para este momento, não se objetiva alcançar uma totalidade dos mesmos, antes, busca-se identificar e compreender os escopos daqueles que foram e/ou ainda são responsáveis pelos encaminhamentos da gestão do turismo desde meados da década de 1970 até a contemporaneidade. 
(a) Megaprojetos turísticos (1970-1980): Foram projetos responsáveis pela criação de infraestruturas (urbanas e turísticas) com vistas em uma maior fluidez de pessoas e mercadorias, já prospectando a abertura para o mercado internacional. Consequentemente, as capitais nordestinas, entre as décadas de 1970 e 1980, passaram a ser vistas como lugares estratégicos, com foco na internacionalização do turismo. As ações dos megaprojetos centralizaram-se no setor hoteleiro. Os megaprojetos turísticos, especializados no nordeste brasileiro foram: (a) Projeto Parque Das Dunas/ Via Costeira (RN); (b) Projeto Cabo Branco (PB); (c) Projeto Costa Dourada (PE, AL) e Projeto Linha Verde (BA). Destaca-se que o papel do Estado nesta conjuntura transitou entre idealizador, empreendedor e financiador, revelando um expressivo grau de interesse (Fonseca, 2005). Outro fato marcante refere-se às obras de recuperação e preservação do patrimônio ambiental. Todos os projetos tiveram que criar novas unidades de conservação e/ou se responsabilizar pelas já existentes. O Parque Nacional de Sete Cidades (PI) e o Parque Estadual das Dunas de Natal (RN) são exemplos desta demanda (Cruz, 2000).

(b) Programa de Desenvolvimento do Turismo-PRODETUR (1991): Surge a fim de sanar os enclaves de infraestrutura, que ainda impediam o Brasil de assumir um lugar de destaque no setor turístico internacional, e o nordeste brasileiro foi à primeira escala contemplada. Assim, a Superintendência do Desenvolvimento do Nordeste (SUDENE) une-se com a EMBRATUR, e em novembro de 1991, criam o PRODETUR (Banco do Nordeste, 2005). Em sua primeira versão, contou com a parceria entre o Governo Federal e os estados, somada com a participação do Banco Interamericano de Desenvolvimento (BID), no papel de financiador, e do Banco do Nordeste (BNB) como órgão executor financeiro (Fonseca, 2005). A fase inicial atuou sob 04 linhas: Melhoria dos acessos; Saneamento básico; Capacitação profissional e Suporte institucional. Os investimentos chegaram ao valor de US\$ 670,00 milhões, assim distribuídos: Aeroportos (34\%), Saneamento básico (24\%), Transportes (12\%), Recuperação do patrimônio histórico (5\%), Desenvolvimento institucional (4\%), Preservação e proteção ambiental (3\%) e outros (18\%) (BNB, 1991; Fonseca, 2005). Nota-se que tanto os Megaprojetos Turísticos (1980) quanto o PRODETUR (1990) trazem a criação de polos turísticos, a saber: Linha Verde (BA), Costa do Sol Poente (CE), Costa Dourada (Municípios do Cabo-PE e Paripueira-Al) (Cruz, 2002; Fonseca, 2005). Motivados pelo êxito da primeira etapa do PRODETUR/NE, fomenta-se uma nova fase para o ano de 1999. Segundo o Banco do Nordeste (2015) a segunda etapa foi direcionada por duas metas: corrigir os enclaves resultantes da primeira fase, e a busca por não repetir tais impactos durante a segunda fase, incorporando para isso, princípios do desenvolvimento sustentável. 
(c) Programa Nacional de Municipalização do Turismo-PNMT (1994): Como saldo do trabalho conjunto entre a Secretaria Nacional de Turismo, com o Ministério da Indústria, Comércio e Turismo, surge o Plano Nacional de Turismo (PLANTUR) que apresentava como principal ação, o PNMT, diante do governo de Fernando Henrique Cardoso (Fratucci, 2008). O referido programa surge por meio da portaria $n^{\circ} 130$, em 30 de março de 1994, visando dotar os municípios brasileiros com apelo turístico, de condições técnicas e organizacionais para promover a atividade, e, sobretudo descentralizar as ações de planejamento. Agregando o município, por meio da difusão das técnicas do planejamento, e incentivando a autonomia diante do fomento dos planos de desenvolvimento (Endres, 2012). Contudo, o PNMT não obteve êxito, devido às limitações financeiras dos municípios, reflexo da política partidária do país, que enfraquece o envolvimento por causas coletivas (Cruz, 2000). Entende-se que a ideia teria tido melhores chances, caso os municípios brasileiros não se encontrassem sucateados e dotados de agudas desigualdades (Fonseca, 2005).

(d) Programas de Ecoturismo para Amazônia Legal-PROECOTUR (2000): Buscava a construção de infraestrutura e o financiamento de empreendimentos turísticos, norteados para a área da Amazônia. Resultado do desempenho do Ministério do Meio Ambiente (MMA), do Ministério do Planejamento, da Superintendência do Desenvolvimento da Amazônia (SUDAM) e da Organização dos Estados Americanos (OEA). O esforço era voltado para combinar a implantação de infraestrutura específica, com a metodologia dos polos (ecoturismo) (Endres, 2012).

(e) Programa de Regionalização do Turismo (PRT) - Roteiros do Brasil (2004): Anunciado como uma política de caráter territorial se tornou referência para a gestão pública do turismo no Brasil desde sua criação, em abril de 2004. Nota-se que a participação dos agentes, se constituiu como a sua principal mola propulsora. O PRT agregou 3.319 municípios brasileiros, abarcando todos os estados do Brasil, mobilizando regiões turísticas por meio de capacitações, segmentações e roteirizações, aprimorando a prestação de serviços e a estruturação dos destinos (Brasil, 2015). Tem como eixos de atuação: Gestão descentralizada do turismo; Planejamento e posicionamento de mercado; Qualificação profissional, dos serviços e da produção associada; Empreendedorismo, captação e promoção de investimento; Infraestrutura turística; Informação ao turista; Promoção e apoio à comercialização e Monitoramento (Programa de Regionalização do Turismo, 2004). Encontra-se atualmente vinculado ao PNT 2013-2016, buscando novos resultados por meio das diretrizes: abordagem territorial, integração e participação social, inclusão, descentralização, sustentabilidade, inovação e competitividade (Brasil, 2015). 
(f) Programa Turismo Sustentável e Infância (2004): Pauta-se na prevenção da exploração sexual de crianças e adolescentes por toda cadeia do turismo brasileiro e concomitantemente, estimular, a proteção ao meio ambiente, à redução da pobreza e das desigualdades regionais. O TSI subdivide-se em quatro eixos: projeto inclusão social com capacitação profissional; projetos de formação de multiplicadores; projetos de formação de multiplicadores e campanhas. O programa já apresenta saldos expressivos desde 2004, entre eles tem-se: 1.800 jovens capacitados profissionalmente; 530 agentes locais formados e 110 mil pessoas mobilizadas (Brasil, 2015).

(g) Projeto Gestão dos 65 Destinos Indutores do Turismo Regional (2007): Resultado da parceria do Mtur, com o Instituto Marca Brasil, o Serviço Brasileiro de Apoio às Micro e Pequenas Empresas (SEBRAE) e a Fundação Getúlio Vargas (FGV) (BRASIL, 2008), o aludido projeto alinha-se com a perspectiva de descentralização, e funciona como suporte para o PRT, configurando-se enquanto ferramenta de planejamento que expõe uma linha estruturante alicerçada em torno de 13 dimensões que buscam estimular a competitividade dos destinos frente os cenários nacional e internacional. Conforme Endres (2012) as 13 dimensões são: infraestrutura geral; acesso; serviços e equipamentos turísticos; atrativos turísticos; marketing; políticas públicas; cooperação regional; monitoramento; economia local; capacidade empresarial; aspectos sociais; aspectos ambientais e aspectos culturais. Concatenadas com essas dimensões, aponta-se ainda 62 variáveis de exame que permitiu a apreciação, por parte dos gestores, da conjuntura de cada destino, considerando-os ou não, como destinos indutores do desenvolvimento turístico. Após análise, elegeram-se os 65 destinos indutores, aptos a receberem investimentos do Mtur (Brasil, 2015, 2008).

(h) Programa Nacional de Acesso ao Ensino Técnico e Emprego-PRONATEC (2014): Consequência da articulação entre o Ministério da Educação (MEC) com o Mtur, o programa surge visando qualificar os trabalhadores do setor de turismo, a fim de melhorar a qualidade no atendimento ao turista. Dentre as formações estão as atividades ligadas ao receptivo, cursos de idiomas e libras. Os participantes são beneficiados por um auxílio financeiro estudantil. Para participar, a idade mínima é de 18 anos e o interessado deve residir em um dos 214 destinos turísticos selecionados. Os cursos são presencias e gratuitos, durando uma média de 04 meses. Dentre as modalidades, é possível citar: Turismo na Empresa, Turismo Cidadão, Turismo e Desenvolvimento local e Turismo social (Brasil, 2015).

\subsection{Principais políticas e planos do turismo brasileiro}


(a) Política Nacional de Turismo (1996/1999): Resultado do empenho do Governo Federal (EMBRATUR e Ministério dos Esportes e do Turismo) surge a Política Nacional de Turismo (PNT), a fim de direcionar as ações dos agentes envolvidos no desenvolvimento turístico brasileiro, sendo planejada para atuar entre os anos de 1996 e 1999, durante o mandato presidencial de Fernando Henrique Cardoso. Para Fratucci (2008) este é o início da tímida organização pública do setor turístico do Brasil. A PNT continha 04 macro estratégias: Ordenamento, desenvolvimento e promoção da atividade pela articulação entre governo e iniciativa privada; Qualificação profissional dos recursos humanos; Descentralização da gestão turística e Implantação de infraestrutura básica e turística adequada às potencialidades regionais (Cruz, 2000). Contudo, (Fonseca, 2005, pp. 87-88) diz que "grande parte das ações [...] acabou esbarrando na fragilidade e na falta de conexão entre a política de turismo com outras políticas setoriais" e assim, o PNT não ultrapassou seu tempo de vigência.

(b) Plano Nacional de Turismo (2003-2007) - diretrizes, metas e programas: Em resposta a falta de continuidade da PNT desde 1999, e visando captar um fluxo internacional, surge o Plano Nacional de Turismo, também decorrente da criação do Mtur em 2003. A plataforma pela qual o PNT 2003/2007 foi elaborado constava com 07 macroprogramas, que dentre seus desdobramentos temáticos, visavam minimizar os problemas e obstáculos que impediam o crescimento do turismo no Brasil, a saber: 1) Gestão e relações institucionais, 2) Fomento, 3) Infraestrutura, 4) Estruturação e Diversificação da Oferta Turística, 5) Qualidade do Produto Turístico, Promoção e 6) Apoio à Comercialização e Informações Turísticas (Brasil, 2003).

(c) Plano Nacional de Turismo (2007-2010): uma viagem de Inclusão: Consequência de dois mandatos sucessivos do Presidente Luís Inácio Lula da Silva, esta nova edição do PNT, favoreceu a continuação das ações iniciadas nos planos passados. Contudo, a meta de consolidar o Brasil como um dos principais destinos turísticos mundiais ainda se fazia presente. De forma paralela, avançava-se na perspectiva da expansão do mercado interno, buscando um planejamento turístico mais equilibrado. A demanda principal era tornar o turismo em um importante canal indutor de inclusão social (Brasil, 2007). Como uma das principais metas do PNT 2007-2010, tem-se a estruturação de 65 destinos turísticos com padrão de qualidade internacional. Aqui iniciava o uso mais enfático de critérios competitivos, nas estratégias governamentais (Brasil, 2007). Esse fato se desdobra no estudo dos destinos indutores do turismo do Brasil, já detalhado na seção anterior.

(d) Plano Nacional de Turismo (2013-2016): o turismo fazendo muito mais pelo Brasil: É o atual PNT, e guia-se através de diretrizes que visam promover o desenvolvimento Revista de Turismo Contemporâneo - RTC, Natal, v. 5, n. 2, p. 238-259, jul./dez. 2017. 
do turismo no Brasil, por meio da descentralização e participação dos distintos agentes. Dentre as principais diretrizes, a ideia de regionalização estrutura todas as ações planejadas, sempre pautadas em uma abordagem territorial. O esforço central do PNT 2013/2016 passa pelas seguintes metas: infraestrutura, financiamento e capitalização do setor, capacitação técnico-gerencial, tratamento fiscal/tributário, inovação tecnológica, promoção interna e externa, certificação, cadastramento, desenvolvimento de micro e pequenas empresas do segmento do turismo, desenvolvimento de destinos turísticos, dentre outros. Este esforço alinha-se com os seguintes objetivos estratégicos: preparar o turismo brasileiro para os megaeventos; incrementar a geração de divisas e a chegada de turistas estrangeiros; incentivar o brasileiro a viajar pelo Brasil e aumentar a competitividade do turismo brasileiro (Brasil, 2014).

A fim de tornar mais didática à compreensão dos instrumentos político-normativos que acompanham o percurso histórico do turismo no Brasil, apresenta-se no Quadro 02, um resumo dos principais esforços em torno da institucionalização do turismo brasileiro. Os dados apresentados complementam os que já foram discutidos, uma vez que algumas iniciativas, de menor expressão, não foram centrais nos debates.

\begin{tabular}{|c|c|}
\hline Instrumentos de Ordenação Política & Conteúdo e/ou Direcionamentos \\
\hline Constituição da Divisão de turismo (1930) & $\begin{array}{l}\text { Primeiro organismo público de turismo. Fiscalizava } \\
\text { atividades das agências de viagem. }\end{array}$ \\
\hline Decreto-lei no $406(04 / 05 / 1938)$ & $\begin{array}{l}\text { Previa no seu art. } 59^{\circ} \text {, a venda de passagens aéreas, } \\
\text { marítimas e terrestres. }\end{array}$ \\
\hline Decreto-lei $1.915(27 / 09 / 1939)$ & $\begin{array}{l}\text { Buscava ampliar o significado do turismo para a } \\
\text { administração pública federal. }\end{array}$ \\
\hline Decreto-lei no $2.440(23 / 07 / 1940)$ & $\begin{array}{l}1^{\circ} \text { diploma sobre a organização de viagens coletivas, } \\
\text { realizadas pelas agências de viagem e turismo e } \\
\text { similares. Impôs um registro junto aos órgãos oficiais } \\
\text { como condição para o funcionamento. }\end{array}$ \\
\hline Decreto-lei44.863 (21/11/1958) & 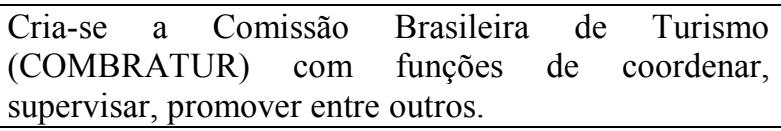 \\
\hline Decreto-lei no $48.126(19 / 04 / 1960)$ & $\begin{array}{l}\text { Aprova o regulamento da COMBRATUR e apresenta } \\
\text { as metas da companhia, como: supervisionar a } \\
\text { execução da PNT. }\end{array}$ \\
\hline Lei n $^{\circ} 4.048(20 / 12 / 1961)$ & $\begin{array}{l}\text { Reorganiza o Ministério da Indústria e Comércio, e } \\
\text { insere a Divisão de turismo. }\end{array}$ \\
\hline Decreto $n^{\circ} 572(02 / 02 / 1962)$ & Extingue a COMBRATUR \\
\hline Decreto-lei no 55(18/11/1966) & $\begin{array}{l}\text { Cria o CNTur e EMBRATUR afim de fomentar a } 1^{\text {a }} \\
\text { PNT. }\end{array}$ \\
\hline Resolução nº 71 (10/04/1969) & $\begin{array}{l}\text { Gera elementos para a elaboração do Plano Nacional } \\
\text { de Turismo (Plantur). }\end{array}$ \\
\hline Decreto-lei 1.191 (1971) & $\begin{array}{l}\text { Cria o primeiro fundo de fomento do turismo no } \\
\text { Brasil (FUNGETUR). }\end{array}$ \\
\hline Decreto-lei nº 71.791 (1973) & $\begin{array}{llll}\begin{array}{l}\text { Dispõe sobre zonas prioritárias } \\
\text { desenvolvimento do turismo. }\end{array} & & \\
\text { dena } & & \\
\end{array}$ \\
\hline Resolução nº 64 do CNTur (1974) & $\begin{array}{l}\text { Define a prestação de serviços turísticos das agências } \\
\text { transportadoras. }\end{array}$ \\
\hline
\end{tabular}




\begin{tabular}{|c|c|}
\hline Decreto-lei ${ }^{\circ} 1.376$ (1974) & $\begin{array}{l}\text { Cria os fundos de investimentos: FINOR, FINAM e } \\
\text { FISET. }\end{array}$ \\
\hline Portaria $\mathrm{n}^{\circ} 3(1976)$ & $\begin{array}{l}\text { Departamento de Aviação Civil autoriza voos } \\
\text { domésticos, solicitados pela EMBRATUR. }\end{array}$ \\
\hline${\text { Decreto-lei } \mathrm{n}^{\circ} 1.485(25 / 10 / 1976)}$ & $\begin{array}{l}\text { Trata de estímulos fiscais ao turismo estrangeiro no } \\
\text { Brasil. }\end{array}$ \\
\hline Lei ${ }^{\circ} 6.513 / 77$ & $\begin{array}{l}\text { Dispõe sobre áreas especiais (áreas naturais) e locais } \\
\text { de interesse turístico. }\end{array}$ \\
\hline Deliberação normativa $n^{\circ} 18$ (1977) & Regulamenta excursões. \\
\hline Megaprojetos turísticos (1970/1980) & $\begin{array}{l}\text { Institui infraestruturas urbanas específicas visando } \\
\text { facilitar a fluidez de pessoas e mercadorias. }\end{array}$ \\
\hline Ano d & $\begin{array}{l}\text { Criam-se os planos: Brasil Turístico Individual (BTI) } \\
\text { e Brasil Turístico em Grupo (BTG). }\end{array}$ \\
\hline Constituição Federal do Brasil (1988) & $\begin{array}{l}\text { I capitulo (Princípios gerais de ordem econômica), no } \\
\text { título III (da ordem econômica e financeira), consta a } \\
\text { menção do turismo pela } 1^{\text {a }} \text { vez na história das } \\
\text { instituições brasileiras, como fator de } \\
\text { desenvolvimento social e econômico. }\end{array}$ \\
\hline Lei $\mathrm{n}^{\circ} 8.181(28 / 03 / 1991)$ & $\begin{array}{l}\text { Revoga o Decreto-lei n.55/66, extingue o CNTur, e } \\
\text { reestrutura a EMBRATUR. }\end{array}$ \\
\hline $\begin{array}{l}\text { Programa de Desenvolvimento do } \\
\text { (PRODETUR/1991) }\end{array}$ & $\begin{array}{l}\text { Buscou sanar os enclaves de infraestrutura no } \\
\text { Nordeste do país. }\end{array}$ \\
\hline Decreto $n^{\circ} 448(14 / 02 / 1992)$ & $\begin{array}{l}\text { Trata da regulamentação da lei } \mathrm{n}^{\circ} \text { 8.181/91, que } \\
\text { institui a finalidade da Política Nacional de Turismo. }\end{array}$ \\
\hline Plantur (1992) & $\begin{array}{l}\text { Instrumento de implementação da política nacional de } \\
\text { turismo, por meio de ações do poder público federal. }\end{array}$ \\
\hline $\begin{array}{l}\text { Política Nacional de Municipalização do Turismo } \\
\text { (1994) }\end{array}$ & $\begin{array}{l}\text { Início do processo de construção de uma diretriz } \\
\text { política do turismo no país, com foco no município. }\end{array}$ \\
\hline 1996- Política Nacional de Turismo & $\begin{array}{l}\text { Continha cinco macros estratégias: implantação de } \\
\text { infraestrutura, capacitação, modernização da } \\
\text { legislação, descentralização da gestão e promoção do } \\
\text { turismo. }\end{array}$ \\
\hline PROECOTUR (Final da década de 1990) & $\begin{array}{l}\text { Construção de infraestrutura básica e o financiamento } \\
\text { de empreendimentos com foco na Amazônia. }\end{array}$ \\
\hline Medida provisória $\mathrm{n}^{\mathrm{o}} 103(01 / 01 / 2003)$ & $\begin{array}{l}\text { Criação do Mtur, visando: promover o turismo } \\
\text { nacional, planejar, coordenar, supervisar e avaliar } \\
\text { planos, programas de incentivo ao turismo. }\end{array}$ \\
\hline Programa de Regionalização do Turismo (2004) & $\begin{array}{l}\text { Focando na região, se constitui como uma das } \\
\text { principais políticas para o desenvolvimento do turismo } \\
\text { brasileiro. }\end{array}$ \\
\hline $\begin{array}{l}\text { Plano Nacional de Turismo: diretrizes, metas e } \\
\text { programas }(2003 / 2007) \text {. }\end{array}$ & $\begin{array}{l}\text { Buscava consolidar o Brasil como um destino turístico } \\
\text { mundial. }\end{array}$ \\
\hline $\begin{array}{l}\text { Plano Nacional de Turismo: uma viagem de Inclusão } \\
(2007-2010)\end{array}$ & $\begin{array}{l}\text { Apresentou uma série de estratégias que buscavam } \\
\text { estimular o mercado interno. }\end{array}$ \\
\hline 65 Destinos indutores do turismo brasileiro & $\begin{array}{l}\text { Objetiva dotar } 65 \text { destinos turísticos, de padrão } \\
\text { internacional. }\end{array}$ \\
\hline Plano Nacional de Turismo (2010-2016) & $\begin{array}{l}\text { Apresenta a regionalização como uma abordagem } \\
\text { territorial e institucional para o planejamento. }\end{array}$ \\
\hline
\end{tabular}

Quadro 02: Levantamento dos principais instrumentos políticos da gestão do turismo no Brasil.

Fonte: Elaborado com base em Cruz (2000, 2002), Fonseca (2005), Dias (2008), Fratucci (2008) \& Endres (2012).

Nota-se, diante da leitura do Quadro 02, que a gestão do turismo no Brasil ao longo do tempo, sofreu impactos e influências de elementos e fatos históricos variados. Pode-se destacar o momento de expressivo intervencionismo estatal, do neoliberalismo, da crise fordista, da chegada da globalização e da implantação dos critérios de competitividade. Ao 
passo que também sofreu intervenção de questões internas, como a falta de prioridade estatal, o entendimento limitado do turismo e a descontinuidade de gestões, os quais retratam em partes, o saldo que se tem do turismo brasileiro na contemporaneidade. Um turismo marcado ainda pela exclusiva movimentação econômica que gera.

\section{ANÁLISES DOS RESULTADOS}

Após discorrer sobre as principais iniciativas, ações e instrumentos políticos que compõem a trajetória histórica do fomento do turismo brasileiro, busca-se a partir deste ponto, analisar a influência e/ou repercussão desses fatos históricos no posicionamento contemporâneo do Estado sobre o turismo no Brasil.

Identifica-se que a falta de preparo para a gestão e para o planejamento do turismo no Brasil é histórica. Recorda-se que as primeiras iniciativas em prol da atividade, entre os anos de 1930 e 1966, configuram-se como ações que tratavam do turismo de forma desarmônica e que não apresentavam estrutura que possibilitasse um ganho de escala e uma maior abrangência. O que de certo modo, configura a inexistência de planejamento, . Alerta que já foi preconizado pelas declarações de Cruz (2000).

Outro aspecto que se pode destacar prontamente é o entendimento limitado do turismo, pautado sob uma interface puramente econômica. Esta é plataforma pela qual o turismo vem sendo justificado enquanto área de prioridade do Estado brasileiro desde 1980 até os dias atuais. Dificultando o necessário alinhamento com um planejamento mais amplo, dotado de estratégias participativas, por parte da gestão pública no Brasil..

Como consequência dessa visão restrita, é possível apontar outra incoerência. Por entender que o objetivo econômico é quem dita o andamento dos processos, o tempo necessário para identificar e maturar qualquer descompasso e/ou imprevisto acaba sendo prejudicado. Ou seja, as ações são projetadas para curto prazo, uma vez que, conforme aponta (Cerqueira et al, 2009, p. 10) é emergente a necessidade de geração de divisas, "em moeda forte o dólar".

Com isso, parece acertado dizer que o turismo no Brasil seguiu os mesmos direcionamentos da atividade no cenário mundial. Ou seja, o turismo revestiu-se de características que acompanham paralelamente à evolução do sistema capitalista, em face do contexto histórico da sociedade industrial.

Legitimando essa fala, sabe-se que o turismo só acontece enquanto atividade de massa após a Segunda Guerra Mundial, em decorrência de fatores como: conquista de tempo livre, diminuição de horas de trabalho, férias remuneradas. Tudo isso somado com a evolução 
dos transportes, a redução das distâncias e a melhoria salarial, fatores que propiciaram o aumento da capacidade de consumo, criando a necessidade básica da viagem de turismo para escapar do stress cotidiano e além do status social. (Castro, 2006).

Esse expressivo afã econômico é quem condiciona as ações à rapidez dos processos, e que acaba afetando a qualidade e o alcance dos resultados. Aqui, sinaliza-se para o exacerbado pragmatismo atual. Uma leitura simplificada e pontual, de um campo do conhecimento repleto de nuances e de interfaces complexas.

Os resultados da pesquisa bibliográfica indicam a presença de algumas metas sobrepostas, de alguns conteúdos contraditórios. Pode-se exemplificar, por meio da experiência do processo de regionalização do turismo brasileiro, iniciado em 2004. Destaca-se que para esta conjuntura, a orientação era voltada para o desenvolvimento sustentável e de base local, com ênfase para a participação integral dos residentes nas ações. Contraditoriamente, os moldes utilizados no programa, pautavam-se em critérios do mercado capitalista, onde produção, consumo e competitividade ainda ditavam as normas (Cruz, 2000 \& Fonseca, 2005).

Destarte, entende-se que não se pode pensar em efetivar ações sustentáveis e com direcionamento de base local, se apoiando em critérios capitalistas que otimizam o ciclo da produção. Percebe-se que este contrassenso ainda vem dificultando a efetivação do que foi planejado pela PRT, e talvez por isso, parte das metas traçadas, tenha ficado no campo das intenções.

Já meditando sobre a década de 1990, período em que o turismo logrou um melhor amparo estatal e inaugurou uma nova era (NET), é possível mencionar alguns elementos que passam a configurar o cenário do turismo no Brasil, e que de certo modo, ainda reverberam nos direcionamentos atuais, sempre pautados na busca por vantagens competitivas, são eles: a busca por elementos da inovação, elevação dos critérios de qualidades dos serviços, o uso de tecnologias integradas e limpas, super segmentações, subjetividades dos sujeitos entre outros elementos que compõem uma gestão do turismo mais globalizada.

Outro direcionamento da década de 1990 é a centralização de ações com vistas a alcançar o mercado internacional, fomentando um modelo de exógeno de desenvolvimento do turismo, estreitando os ganhos e a participação dos residentes locais, diante dos processos envolvidos.

Porém este posicionamento modifica-se no decorrer do tempo, devido circunstâncias especificas. Quando o mercado externo começa a se retrair, prontamente o Estado direciona seus esforços em torno da captação de um fluxo doméstico, visando assegurar a balança 
comercial do turismo. Ainda é possível identificar o redirecionamento para um turismo doméstico na contemporaneidade, por meios dos esforços e diante da instabilidade do mercado global (Cerqueira et al, 2009).

Ao se tratar da fragilidade da gestão pública do setor turístico no Brasil, destaca-se também, a falta de expressão política do turismo no Brasil, predicado que marca a atividade. Mesmo com a criação do Ministério do Turismo em 2003, o turismo ainda padece de representatividade política, ratificada inclusive, no processo de seleção do ministro, onde critérios técnicos são negligenciados, e questões político-partidárias assumem a escolha. $A$ priori, entende-se que a falta de preparo para gerir o turismo, acabou provocando sérios danos, na forma tímida com que a atividade vem se estruturando no Brasil ao longo do tempo, mesmo em épocas que o Estado já norteava ações, de forma mais enfática, ou seja, desde 1971.

Ainda é permitido citar que, a descontinuidade política atinge diretamente as metas pensadas para o turismo no Brasil. No decorrer da história até os dias atuais, é possível pontuar que, em face de mandatos presidenciais sequenciais, os ganhos são mais fáceis de ser identificados. Infelizmente o inverso também ocorre, só que em maior expressão.

\section{CONSIDERAÇÕES FINAIS}

Evidencia-se diante das análises, que a gestão pública do turismo no Brasil, apesar de pontuais avanços, foi marcada e continua ressignificando alguns equívocos que limitam os progressos, quando comparados ao potencial turístico que o país detém. Parece acertado concluir diante das análises, que as primeiras ações do turismo no Brasil, na década de 1930, estavam alinhadas aos serviços básicos de viagens, solicitando ações centradas em demandas instantâneas. Enfatiza-se que as ações estatais só sucediam, mediante a ocorrência dos fatos.

Com o passar do tempo, o turismo ganha importância econômica, fato que aponta esta vertente como a responsável pela rápida difusão da atividade em escala mundial, repercutindo em nível nacional, na captação de investimentos, no surgimento de cursos superiores e técnicos de turismo e de pesquisas, dentre outros.

O viés econômico norteia grande parte das ações públicas que se pautam no fomento do turismo. Guiando as escolhas gerenciais em direção ao lucro e buscando soluções de curto prazo. Raramente o turismo foi e/ou é pensado como uma política pública de escopo maior, que vise proporcionar lazer, bem- estar e participação integral do residente.

Entende-se que quando a visão econômica limita à compreensão do turismo, enquanto fenômeno, ela acaba fazendo com que as ações promovidas pelo poder público 
ratifiquem os hiatos sociais já existentes no país, contrariando a ideia tão difundida nos discursos políticos que tratam do turismo, como uma possibilidade de minimizar desigualdades regionais.

Fica patente que se inexiste um olhar prospectivo do Estado para o turismo, consequentemente inexistem políticas públicas, órgãos, pesquisas entre outros desdobramentos pautados no avanço e nas relações entre as outras interfaces do turismo, como a social, cultural dentre outras. Assim, observa-se a necessidade de avançar no entendimento do turismo, buscando planejá-lo como uma área multissetorial, tornando possível a busca de resultados mais equilibrados para todos os agentes que atuam nele.

Conclui-se, pois, que a ampliação do significado é ponto de partida para o inicio da mudança na forma como o turismo é pensado pelo Estado no Brasil. Ressalta-se que simultâneo à aplicação de novas percepções, é imprescindível agenciar uma mudança na cultura política e administrativa, buscando novas estruturas e formas de gestão.

Reconhece-se que o turismo começa a solicitar entendimentos mais holísticos de seus agentes, com vistas em um desenvolvimento mais participativo. Faz-se necessário pensar no turismo de forma mais endógena. Buscando o devido equilíbrio das demandas internas, como um pré-requisito para as intervenções de repercussão externa.

\section{REFERÊNCIAS}

Banco do Nordeste. (2005). Programa de Desenvolvimento do Turismo no Nordeste. Memorando do Banco do Nordeste do Brasil S.A. Relatório final do Projeto BR-0204. Recuperado em 10 de julho, 2015, de http://edi.bnb.gov.br/content/aplicacao/prodetur/downloads pdf.

. (1991). Prodetur/NE II: Histórico e objetivos. Recuperado em 12 de novembro, 2015, de http://www.bnb.gov.br/web/guest/objetivos2.

Brasil, M. T. (2015). Documento referencial - Turismo no Brasil 2011-2014. Recuperado em 22 de junho, 2015, de http://www.dadosefatos.turismo.gov.br.

. (2015). Avaliação do Programa de Regionalização do Turismo - Roteiros do

Brasil. Recuperado em 22 de junho, 2015, de http://www.turismo.gov.br/sites/default/turismo/o_ministerio/publicacoes/downloads_publica coes/Livro_Regionalizaxo.pdf.

Turismo. 42, Brasília.

. (2014). Anuário estatístico do turismo-2015. Secretaria Nacional de Políticas de . (2008). Estudo de Competitividade dos 65 Destinos Indutores do Desenvolvimento Turístico Regional - Relatório Brasil. (2ª ed), Brasília. 
. (2007). Plano Nacional de Turismo (2007-2010): uma viagem de Inclusão. Recuperado em 12 de junho, 2015, de http://www.turismo.gov.br.

. (2004). Programa de Regionalização do Turismo: diretrizes Secretaria Nacional de Políticas de Turismo. Brasília.

. (2003). Plano Nacional de Turismo 2003-2007: diretrizes, metas e programas. Recuperado em 10 de junho, 2015, de http://www.turismo.gov.br/.

Castro, N. A. R (2006). O lugar do turismo na ciência geográfica: contribuições teóricometodológicas à ação educativa. Tese (Doutorado em Geografia) - Universidade de São Paulo, São Paulo.

Cruz, R. C. (2002). Politicas públicas de turismo no Brasil: significado, importância, interfaces com outras políticas setoriais. UNB/MMA, Brasília. . (2000). Política de turismo e território. Contexto, São Paulo.

Dias, R. (2008). Planejamento do turismo: política e desenvolvimento do turismo no Brasil. Atlas, São Paulo.

Endres, A. V. (2012). As políticas de turismo e os novos arranjos institucionais na Paraíba/Brasil. Tese (Doutorado em Sociologia Política) - Programa de Pós-Graduação em Sociologia Política, Universidade Federal de Santa Catarina, Florianópolis-SC.

Fratucci, A. C. (2008). A dimensão espacial nas políticas públicas brasileiras de turismo: as possibilidades das redes regionais de turismo. Tese (Doutorado em Geografia) - Programa de Pós-Graduação em Geografia, Universidade Federal Fluminense, Rio de Janeiro-RJ.

Fonseca, M. A. (2005). Espaço, Políticas de Turismo e Competitividade. Edufrn, Natal.

Harvey, D. (2008). Condição pós-moderna: uma pesquisa sobre as origens da mudança cultural. Ed.Loyola, São Paulo.

Köche, J. C. (2013). Fundamentos de metodológica científica: teoria da ciência e iniciação à pesquisa. Vozes, Rio de Janeiro.

Oliveira, M. F., \& Oliveira, O. J. (2012). Estado e turismo: trajetórias do caso baiano. Caderno Virtual de Turismo, 12(3), 384-398.

Porter, M. (1998). Estratégia: a busca da vantagem competitiva. Rio de Janeiro.

Solha, K. T. (2004). Órgãos públicos estaduais e o desenvolvimento do turismo no Brasil. Tese (Doutorado em Relações públicas, propaganda e turismo) - Escola de Comunicações e Artes (ECA). Universidade de São Paulo, São Paulo.

Veal, A. (2011). Metodologia de pesquisa em lazer e turismo. Aleph. Série turismo, São Paulo. 